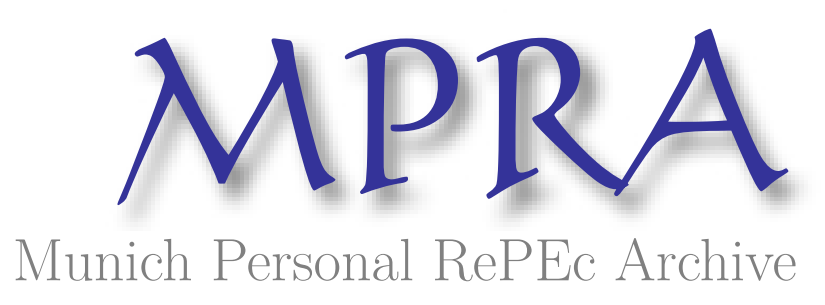

\title{
Jawaharlal Nehru and Science and Technology
}

\author{
Tyabji, Nasir
}

June 2007

Online at https://mpra.ub.uni-muenchen.de/82979/

MPRA Paper No. 82979, posted 30 Nov 2017 11:19 UTC 


\title{
Jawaharlal Nehru and Science and Technology
}

\author{
Nasir Tyabji
}

Jawaharlal Nehru is, of course, identified in the public mind with the tireless advocacy of the intrinsic link between science and development. In the early years after independence this association was generally perceived in a positive spirit, as was the notion of India's transition to modernity, with which this linkage was generally connected. However, sometime in the late 1970s, a current of disenchantment with the ecological, social and cultural effects of development projects set in. This was because of the chasm between those sections of society that benefited from the projects and those that bore the direct costs incurred in the construction of these projects, in terms of the disruption of their culture and means of livelihood. The association that these projects in themselves were perceived to have with the Nehruvian vision (rather than the authoritarian manner of their implementation) led to an increasing alienation of some sections of the intelligentsia from this vision. This period, coinciding with the first stirrings of the liberalization process which was associated with the 1976 budget, led to a more general questioning of Nehru's legacy, in the doctrines of Nehruvian socialism.

Science also played a role in the second feature of the Nehruvian vision, which consisted of the process of building a secular society. Here it was the creation, on a mass scale, of what came later to be termed as the "scientific temper" that was the aim to be achieved. This, too, became the subject of violent controversy in the years leading up to the upsurge in communal forms of nationalism in the mid 1980s. With this, Nehruvianism itself faced an eclipse which was accelerated by the ascendancy of the economic ideology underpinning the unfettered process of economic liberalization initiated by the 1991 budget. It is only now, almost thirty years after the criticism began, that a new appraisal of Nehruvianism is beginning to take place, the defining feature of this new phase being the political fallout of the 2004 elections. This fallout has created the space which allows for a reorientation from the purely defensive strategies which had necessarily to be adopted during the period when the forces of communal nationalism were directly in control of the government.

In the meanwhile a major issue that has entered the centre space of the Indian political and social arena is that of empowerment. This issue has expanded in scope from the constitutionally ordained affirmative action in favour of the dalits and the tribal people to the other, largely peasant, communities which fall within the category of the other backward castes. To this must be added the women's question. Although this last had been an integral part of the national movement, not only as a part of Gandhian thought, but was actually the subject of deliberation by a subcommittee of the National Planning Committee, it achieved new salience in the 1970s with the growth of the women's movement.

The question is then of the degree to which Nehru's vision of the role of science and technology is able to encapsulate these new aspirations, rather for a form of development 
that incorporates these aspirations. It is a well known characteristic of Jawaharlal Nehru that many of his statements of intention were made as an individual, and amounted to statements of personal vision. Frequently, they were not operationalised into Congress strategy before Independence or form a part of Government policy after independence. This was also true of his observations on the role of science, often made while inaugurating sessions of the Indian Science Congress. However, the 1958 Science Policy Resolution stands on a different footing. ${ }^{1}$ As a Statement of Government policy, it had to be processed by the relevant agencies of the government and represented a collective view of the role of science in the developmental process. However, even though it was drafted by Homi Bhabha, it had the imprint of Nehru's personal vision. It is interesting to return to this document to answer the question of the durability of Nehru's vision on science and technology, almost 50 years after it was published.

The Scientific Policy Resolution is, unlike the Industrial Policy Resolution of 1956, a short document consisting of seven paragraphs. The first paragraph itself shows an unusual perception of the determinants of development when it states:

The key to national prosperity, apart from the spirit of the people, lies, in the modern age, in the effective combination of three factors, technology, raw materials and capital, of which the first is perhaps the most important, since the creation and adoption of new scientific techniques can, in fact, make up for the deficiency in natural resources, and reduce the demands on capital. But technology can only grow out of the study of science and its application.

The unusual feature here is, of course, the reference to the spirit of the people as one of the key factors. The reference here is clearly to the imperative of arousing the enthusiasm of the bulk of the people, for in the absence of their active participation, the process of development would be slowed down if not thwarted. ${ }^{2}$

The critical nature of the impact of science in altering the consciousness of the people continues to be emphasised in the second paragraph:

The dominating feature of the contemporary world is the intense cultivation of science on a large scale, and its application to meet a country's requirements. It is this, which, for the first time in man's history, has given to the common man in countries advanced in science, a standard of living and social and cultural amenities, which were once confined to a very small privileged minority of the population.

\footnotetext{
${ }^{1}$ Government of India, Scientific Policy Resolution, March 4, 1958, No. 131/CF/57, New Delhi

${ }^{2}$ At another, more technical level, the resolution shows an obsolete notion of the relationship between science and technology in the assertion that "...technology can only grow out of the study of science and its application." This representation of a linear relationship between science and technology, later characterized as the ladder approach was replaced with a more nuanced understanding when Toyotaism introduced the cyclical relationship.
} 
The critical point to be noted here is the use of the word "cultivated" in association with science, as compared to the more mundane reference to the application of science. This surely implies that science is first to be imbibed, and then be actively applied, not only by scientific agencies, but also by the bulk of the population.

The second paragraph continues:

Science has led to the growth and diffusion of culture to an extent never possible before. It has not only radically altered man's material environment, but, what is of still deeper significance, it has provided new tools of thought and has extended man's mental horizon. It has thus influenced even the basic values of life, and given to civilization a new vitality and a new dynamism.

It is thus the spread of the scientific temper which not only leads to the spread of culture but also invigorates preexisting cultures, providing for a more inclusivist process of growth. Indeed, the spread of the scientific temper is critical to the growth of the productive forces and the provision of economic, social and cultural amenities that this provides.

It is only through the scientific approach and method and the use of scientific knowledge that reasonable material and cultural amenities and services can be provided for every member of the community, and it is out of recognition of this possibility that the idea of a welfare state has grown. It is characteristic of the present world that the progress towards the practical realization of a welfare state differs widely from country to country in direct relation to the extent of industrialization and the effort and resources applied in the pursuit of science.

This formulation, that the progress towards the achievement of a welfare state depends on the degree of industrialization achieved, marks the transition in the policy resolution from a discussion of science to that of technology. Before turning to the question of technology, it may be emphasized here that at the conceptual level, the question of the role of science has been expounded in an extremely sophisticated way. The familiar problems that plague the practice of science in India are not due to the vision which underlay it. These problems, which have prevented science from fulfilling the developmental goals so eloquently described in the Scientific Policy Resolution, are due to three main reasons. The first is the creation of structures of scientific research (CSIR, the Department of Atomic Energy, and the Defence Research and Development Organisation) outside the framework of the university system. Secondly, this weakening of the university research effort caused by the drainage of scientists from the universities into organizations offering comparatively better career prospects, has been compounded by the concentration of research funds precisely on these three organizations. Finally, this concentration has led to the domination of not only "big science", but more corrosively, on the overwhelming emphasis to the problems of the defence of the state, or at least, to the formulation of problems as perceived by the state. The net result has been that the option of utilizing the transformative powers of science potentially realisable by relating science to the aspirations of the people was consciously rejected. Campaigns for the 
inculcation of the scientific temper, for instance, had sporadic existence rather than forming a component part of the science activity itself.

On the question of technology, the Scientific Policy Resolution descends to a disappointingly mundane plane. In the fourth paragraph it is stated that:

The wealth and prosperity of a nation depend[s] on the effective utilization of its human and material resources through industrialization. The use of human material for industrialization demands its education in science and training in technical skills. Industry opens up possibilities of greater fulfillment for the individual. India's enormous resources of manpower can only become an asset in the modern world when trained and educated.

The key feature to note in this paragraph, the only mention of the human factor in this part of the resolution, is the instrumentalist view not only of the role of scientific and technical training, but of the human being itself. It is reduced to an input to production, qualitatively at the same level as the material resources. This is, of course, consistent with the homogenized approach to factors of production in the neo classical analysis of economics, but represents a surprising change of gear within the Scientific Policy Resolution. It also signifies a conception of technology, the area of knowledge underlying the production process, and thus of industrialization, which is exclusively "engineering" in conception.

From the work of Frederick Taylor dating to a century ago, it has been made evident that the human process of work, or the labour process, is an intrinsic part of the production process. Production can only take place with the combination of the labour process with the physical process of the conversion of the raw materials into finished commodities. Following Taylor's research, the explicit understanding of the need to incorporate the labour process into manufacture was exemplified by the Fordist innovation of the production line and this understanding has continued with the work procedures within contemporary Toyotaism. The approach to understanding the labour process, however, is from a managerial perspective, basing itself on the need to control the process rather than viewing it as an opportunity to empower labour, though Toyotaism does mark an advance over Fordist production methods in this respect. However, the achievement of collective bargaining rights by the labour movement in advanced industrial economies has also brought the concept of the labour process into general recognition though, again, this is from a managerial perspective.

Labour relations in India did not evolve into Taylorism in the pre independence period. ${ }^{3}$ Arising from this, the concept of true collective bargaining has not been recognized in law, even after independence. Following the adoption of the model of arbitration, initially introduced by Gandhi into the Ahmedabad industrial milieu, this approach was first extended by law to the whole of Bombay Presidency by the late 1930s, and to the rest of

\footnotetext{
${ }^{3}$ See, for example, Arup Kumar Sen "Mode of Labour Control in Colonial India" Economic and Political Weekly XXXVII (2002), 38: 3956-3966
} 
India by the time of independence. ${ }^{4}$ Underlying Indian labour relations legislation is the view that the State must be in a position to arbitrate. Provision for the enduring role of the state has distorted the process of negotiation between management and workers and effectively prevented the true development of collective bargaining. ${ }^{5}$

Unlike the situation with regard to science, therefore, where the Scientific Policy Resolution could start de novo, technology was an area where existing forms of the social relations within production prevented the development of a conception of the work process, particularly that conception which was empowering for workers. The entire history of post independence developments militated against the recognition, let alone the operationalising, of such a notion of the relationship between workers and management. The Congress inspired split in the labour movement, signified by the breaking away of the Indian National Trade Union Congress (INTUC) from the All India Trade Union Congress (AITUC) in the period immediately preceding independence, while ensuring that the Congress retained a base within the labour movement, was fatal for the creation of a collective bargaining framework. This development, largely the handiwork of the trade union leaders within the Congress, supported by Sardar Patel, probably was not within Nehru's power to control. However, what is surprising is the fact that when, a few years after independence, V V Giri, Labour Minister in Nehru's Cabinet, wished to introduce a Bill amending the Industrial Disputes Bill the matter was allowed to drag on for several months. Finally, Nehru suggested that Giri discuss the amending bill with TT Krishnamachari, Minister for Commerce and Industry, an unusual person to select, given that given his portfolio, he would represent the employers of labour. Eventually, the Bill was allowed to lapse after Giri left the Ministry. Subsequent Labour Ministers did not show equal determination to introduce formal collective bargaining.

Although the connection would be difficult to establish without further detailed research, it seems plausible to conclude that the sharp contrast between the democratic and sophisticated associations drawn between the role of the human being and the role of science in development are missing in the discussion of industrialization because of the historical events outlined above. The organization of science presented undoubted problems in preventing the growth of dysfunctional hierarchies, and the imperatives of perceived state priorities was to prevent science playing a liberatory role, in the overall scheme, science was not central to the political economy. The organization of industry, on the other hand, was a defining feature of this political economy, and it was not possible to postulate a social arrangement within the production process which was at odds with the prevailing hierarchy.

The Nehruvian vision of Science and Technology as embodied in the Scientific Policy Resolution was a far seeing document of statement of intent. As far a science is concerned, though the actual practice of science was far removed from the vision, this hiatus is capable of being corrected if the social forces presently excluded from, or marginalized by, the development process are enabled to assert themselves. However, the

\footnotetext{
${ }^{4}$ Sujata Patel The Making of Industrial Relations (New Delhi, Oxford University Press: 1987)

${ }^{5}$ Debi S. Saini "Labour Legislation and Social Justice: Rhetoric and Reality" Economic and Political Weekly XXXIV (1999), :L32-L40
} 
perspective on technology is lacking in complementary depth. It is the premise of this paper that the mechanical conception of the human role in production stems from the actual social role to which workers are confined by the existing industrial relations system. In this case, the postulates of the Scientific Policy Resolution themselves require to be restated in accordance with the social aspirations of the time. 